\title{
Impact Toughness Modification of NIST Low-Energy Charpy Verification Specimens for Testing at Room Temperature
}

\author{
Enrico Lucon and Ray L. Santoyo \\ National Institute of Standards and Technology, \\ Boulder, CO 80305, USA \\ enrico.lucon@nist.gov \\ raymond.santoyo@nist.gov
}

\begin{abstract}
The possibility for the National Institute for Standards and Technology (NIST) to certify Charpy reference specimens for testing at room temperature $\left(21^{\circ} \mathrm{C} \pm 1{ }^{\circ} \mathrm{C}\right.$ ) instead of $-40{ }^{\circ} \mathrm{C}$ was investigated in a previous study, in which a slightly increased likelihood of specimen jamming was observed at the low-energy level (13 J to $20 \mathrm{~J}$ ). Moreover, there is a concern that the higher impact toughness of low-energy verification specimens at room temperature would not allow the same Charpy machine features to be verified as in the case of low-temperature $\left(-40^{\circ} \mathrm{C}\right)$ tests, namely, the linear elastic behavior of the sample and the very high maximum forces (typically larger than $33 \mathrm{kN}$ ). In this paper, we report on the change in the mechanical properties (hardness and absorbed energy) of the American Iron and Steel Institute (AISI) 4340 steel low-energy specimens that ensues from the modification of the temperature of the final tempering heat treatment. We established that, if low-energy verification specimens are tempered at $300{ }^{\circ} \mathrm{C}$ for $2 \mathrm{~h}$ and then air cooled, they exhibit equivalent impact toughness (13 J to $20 \mathrm{~J}$ ) and postimpact behavior (specimen halves projected backward at high speed) at room temperature as compared to specimens currently on sale for testing at $-40^{\circ} \mathrm{C}$. Their hardness is however increased to above $49 \mathrm{HRC}$ on the Rockwell scale. The minimum hardness requirement for low-energy verification specimens, currently set at 44 HRC in NIST specifications, will have to be increased to 49 HRC.
\end{abstract}

Key words: AISI 4340 steel; Charpy reference specimens; impact toughness; minimum hardness; postimpact behavior; specimen jamming; tempering heat treatment.

Accepted: March 16, 2017

Published: March 27, 2017

https://doi.org/10.6028/jres.122.023

\section{Introduction}

During the past 27 years, NIST has supplied industries and institutions in the United States and around the world with certified Charpy V-notch reference specimens for the indirect verification of impact machines in accordance with the American Society for Testing and Materials (ASTM) E23 standard [1]. The indirect verification of Charpy machines was added to ASTM E23 more than 50 years ago as a means to reduce the scatter of Charpy test results and ensure the correct operation and maintenance of impact machines [2]. The U.S. Army (Watertown Arsenal, Advanced Manufacturing and Mechanical Reliability Center) originally developed the Charpy Verification Program, and in 1989, NIST assumed that responsibility.

Three Charpy machines located at NIST in Boulder, Colorado, are used to qualify verification specimens and produce certified values of absorbed energy $(K V)$. These machines are indicated as "reference machines" in ASTM E23-16b.

Every year, the Charpy program at NIST evaluates the indirect verification results of more than 1500 industrial machines from all over the world. To be certified for acceptance testing in compliance with the requirements of ASTM E23, the average test results of a customer's machine at a minimum of two different 
energy levels have to agree with the certified $K V$ values established on the NIST master machines within the greater of $1.4 \mathrm{~J}(1 \mathrm{ft} \cdot \mathrm{lb})$ or $5 \%$.

Since the Charpy verification program was launched at the Watertown Arsenal in the 1950s, the test temperature for both low-energy (13 J to $20 \mathrm{~J}$, Standard Reference Material [SRM] 2092) and high-energy (88 J to $136 \mathrm{~J}$, SRM 2096) specimens has always been prescribed as $-40{ }^{\circ} \mathrm{C}\left(-40^{\circ} \mathrm{F}\right)$. In the mid-1990s, verification specimens for a third absorbed energy level (super-high energy, $176 \mathrm{~J}$ to $244 \mathrm{~J}$, SRM 2098) were introduced, and those have to be tested at room temperature (RT, $21^{\circ} \mathrm{C} \pm 1{ }^{\circ} \mathrm{C}$ ).

Over the years, numerous customers have approached NIST to enquire about the possibility of verifying their machines by testing reference specimens at $\mathrm{RT}$ rather than at $-40{ }^{\circ} \mathrm{C}$, particularly when most or all of their Charpy testing is carried out at RT. Note also that most of the other producers of Charpy verification specimens in the world only require testing at RT [3].

\section{Previous Investigation: Feasibility Study on NIST RT Verification Specimens}

In 2015, a feasibility study was conducted at NIST [3] to evaluate the possibility of changing the test temperature of NIST low- and high-energy verification specimens from $-40{ }^{\circ} \mathrm{C}$ to $21^{\circ} \mathrm{C}$ without significantly altering the operations of the Charpy program or the accuracy of the machine verification procedures. The results clearly indicated that in most cases, the variability of the impact test results decreases when testing at RT, and therefore the change in test temperature actually enhanced the quality of the SRMs produced by NIST.

The only significant issue that emerged from the 2015 investigation derived from the fact that for one of the low-energy lots (out of three tested), a small number of specimens (2 out of 30) jammed (i.e., failed to clear the anvils) and consequently provided unusually high absorbed energy values, which were statistically classified as outliers. Jamming only occurred when one of the master machines (identified herein as "TK") was used; it is the only one with a C-shaped hammer. It was also observed that, for most impact tests performed at $21^{\circ} \mathrm{C}$ on low-energy specimens, the two broken halves tended to remain close to the impact area (where supports and anvils are located) rather than flying out from the back of the machine with significant kinetic energy, as normally occurs at $-40{ }^{\circ} \mathrm{C}$. This different postimpact behavior of the broken sample is a consequence of the higher impact toughness of the steel at RT (about $10 \%$ higher than at $-40{ }^{\circ} \mathrm{C}$ according to the study in Ref. [3]), and it causes specimen jamming at $21{ }^{\circ} \mathrm{C}$ to be slightly more likely for a machine equipped with a C-shaped hammer.

An additional objection to the test temperature change of low-energy specimens came from technical discussions with one of the major Charpy machine producers, who speculated that the tougher behavior of the samples at RT could render the low-energy verification less severe for the machine (namely, the maximum force recorded during the test decreases if specimen toughness increases).

The two issues mentioned here prompted us to seek a relatively simple, yet effective, procedure for modifying the impact toughness of NIST low-energy specimens, so that the results of RT tests can be considered fully equivalent to those currently obtained at $-40^{\circ} \mathrm{C}$.

\section{4340 Steel: Material and Heat Treatments for Low-Energy Specimens}

Both the low- and high-energy SRMs are made from AISI 4340 steel bars from a single heat to minimize compositional and microstructural variations. The nominal composition of the 4340 steel is shown in Table 1.

Table 1. Chemical composition of 4340 steel, mass fraction (\%).

\begin{tabular}{|cccccccc|}
\hline $\mathbf{C}$ & $\mathbf{S i}$ & $\mathbf{M n}$ & $\mathbf{P}$ & $\mathbf{S}$ & $\mathbf{M o}$ & $\mathbf{N i}$ & $\mathbf{C r}$ \\
\hline 0.4 & 0.28 & 0.66 & 0.004 & 0.001 & 0.28 & 1.77 & 0.83 \\
\hline
\end{tabular}


The steel is produced by a double-vacuum-melting procedure (vacuum-induction-melt and vacuumarc-remelt), in order to minimize elements such as $\mathrm{P}, \mathrm{S}, \mathrm{Va}, \mathrm{Nb}, \mathrm{Ti}$, and $\mathrm{Cu}$.

For low-energy specimens (absorbed energy $=13 \mathrm{~J}$ to $20 \mathrm{~J}$ at $-40{ }^{\circ} \mathrm{C}$ ), the following heat treatment had been recommended by the Army Materials Technology Laboratory [4]:

(a) Normalization at $900^{\circ} \mathrm{C}$ for $1 \mathrm{~h}$, followed by air cool.

(b) Austenitization (neutral hardening) at $871^{\circ} \mathrm{C}$ for $1 \mathrm{~h}$, followed by oil quench.

(c) Tempering at $400{ }^{\circ} \mathrm{C}$ for $1.5 \mathrm{~h}$, followed by oil quench.

The resulting hardness was prescribed to be $46 \mathrm{HRC} \pm 1$ HRC (Rockwell scale C).

Note that, in order to produce high-energy specimens (absorbed energy $=88 \mathrm{~J}$ to $136 \mathrm{~J}$ ), the final tempering (step c) had to be performed at $593^{\circ} \mathrm{C}$ for $1.25 \mathrm{~h}$, also followed by oil quench. The expected hardness was in the range $32 \mathrm{HRC} \pm 1$ HRC.

For large production lots of verification specimens (1200 specimens or more), additional steps can be used to fine-tune the process, such as double tempering, stress relief, cryotreatment, etc. In this case, extremely well controlled processing is needed to attain coefficients of variation ${ }^{1}$ of 0.04 or lower.

Currently, the NIST Charpy program uses four different vendors for the procurement of Charpy verification specimens. Upon request to disclose information about the heat treatment steps used in the preparation of the specimens, only one of the vendors (identified here as "A") complied, while the remaining vendors ("B," “C," and "D") either did not respond or claimed confidentiality of the information. For this investigation, we therefore used specimens from one of the low-energy lots from vendor A, identified as lot LL-161, including about 2000 specimens. For this lot, the heat treatment consisted of the following steps ${ }^{2}[5]$ :

(a) Normalization, followed by controlled increase of temperature.

(b) Furnace cooling, followed by gas cool.

(c) Quench hardening.

(d) Air cool.

(e) Wash.

(f) Tempering.

(g) Deep freeze.

(h) Final tempering, followed by air cooling.

For high-energy specimens, the final tempering (step $h$ ) is performed at a higher temperature. The temperature of the final tempering $\left(T_{\mathrm{FT}}\right)$ has a significant influence on the impact toughness level of the Charpy specimens, as will be shown by the results of this study.

\section{Test Equipment and Results Obtained}

All Charpy tests were performed on the TK master machine in Boulder. The main characteristics of this machine are listed in Table 2.

Table 2. Characteristics of the TK impact machine.

\begin{tabular}{|c|c|c|c|c|c|c|}
\hline $\begin{array}{c}\text { Pendulum } \\
\text { type }\end{array}$ & $\begin{array}{c}\text { Capacity } \\
\text { (J) }\end{array}$ & $\begin{array}{c}\text { Hammer } \\
\text { weight (N) }\end{array}$ & $\begin{array}{c}\text { Impact } \\
\text { velocity }(\mathrm{m} / \mathrm{s})\end{array}$ & $\begin{array}{l}\text { Hammer } \\
\text { length (m) }\end{array}$ & $\begin{array}{c}\text { Falling } \\
\text { height (m) }\end{array}$ & $\begin{array}{c}\text { Falling } \\
\text { angle }\left({ }^{\circ}\right)\end{array}$ \\
\hline C & 359.5 & 295.3 & 4.89 & 0.90 & 1.22 & 110.7 \\
\hline
\end{tabular}

Rockwell C (HRC) hardness measurements were performed in compliance with ASTM E18-16.

In order to investigate the dependence of the absorbed energy on $T_{\mathrm{FT}}$ for lot LL-161, we asked vendor A to send us 15 Charpy specimens pulled out from the lot after step (f), in a condition that we will designate "untempered" (UT).

\footnotetext{
${ }^{1}$ Coefficient of variation: ratio between standard deviation and average absorbed energy.

${ }^{2}$ Details of the heat treatment (temperatures, heating/cooling rates, durations, etc.) are proprietary information and are therefore kept confidential.
} 
For the fully heat-treated (FHT) specimens of LL-161, the hardness and impact results shown in Table 3 were obtained during pilot lot ${ }^{3}$ testing. Table 3 also includes the results of two RT Charpy tests performed on FHT specimens from the same pilot lot. Note that all Charpy tests documented in Table 3 were performed on the TK machine (i.e., the one for which jamming had been observed in our previous investigation).

Table 3. Test results for fully heat-treated Charpy specimens of LL-161 on the TK machine $(\overline{K V}=$ mean absorbed energy; $v=$ velocity of the broken specimen halves after impact).

\begin{tabular}{|c|c|c|c|c|c|c|}
\hline Condition & HRC & $\begin{array}{c}T \\
\left({ }^{\circ} \mathbf{C}\right)\end{array}$ & $\begin{array}{l}\text { Number of } \\
\text { tests }\end{array}$ & $\begin{array}{l}K V \\
(J)\end{array}$ & $\begin{array}{l}\text { Postimpact behavior } \\
\text { Direction of travel }\end{array}$ & Speed \\
\hline \multirow[b]{2}{*}{ FHT } & $47.3^{\mathrm{a}}$ & -40 & 25 & $14.42^{\mathrm{b}}$ & Backward & High \\
\hline & $\begin{array}{l}46.8 \\
47.2\end{array}$ & 21 & 2 & $\begin{array}{l}18.48 \\
17.78\end{array}$ & $\begin{array}{l}\text { Test 1: } 1 / 2 \text { forward, } 1 / 2 \text { on base (front) } \\
\text { Test 2: backward }\end{array}$ & Low \\
\hline
\end{tabular}

${ }^{\mathrm{b}}$ Average value from the 25 tests.

Table 3 also includes information about the postimpact behavior of the tested specimens, which affects the likelihood of jamming. When the broken specimen halves are ejected backward ${ }^{4}$ at high speed, jamming is basically impossible. As the kinetic energy of the Charpy halves decreases, the likelihood of jamming increases, and becomes highest when both broken halves fall on the base of the machine. When tested at $-40^{\circ} \mathrm{C}$, the current low-energy specimen halves fly backward at high speed, while high-energy specimens are pushed forward by the swinging hammer at medium speed.

Two of the 15 untempered (UT) specimens received from vendor A were impact tested at RT, after performing hardness measurements (Table 4).

Table 4. Test results for UT specimens of LL-161.

\begin{tabular}{|c|c|c|c|c|c|c|}
\hline Condition & HRC & $T$ & Number of & KV & Postimpact beh & jior \\
\hline Conaitio & & $\left({ }^{\circ} \mathrm{C}\right)$ & tests & (J) & Direction of travel & Speed \\
\hline UT & $\begin{array}{l}54.5 \\
54.5\end{array}$ & 21 & 2 & $\begin{array}{l}27.07 \\
26.26\end{array}$ & Backward & High \\
\hline
\end{tabular}

With respect to FHT specimens (Table 3), UT specimens are significantly harder, and their RT impact toughness is $47 \%$ higher. Their absorbed energy is outside the typical range of low-energy specimens (13 J to $20 \mathrm{~J}$ ). Their postimpact behavior is equivalent to that of FHT specimens tested at $-40{ }^{\circ} \mathrm{C}$ (halves ejected backward at high speed).

The influence of the tempering temperature on the mechanical properties (hardness, tensile strength, toughness) of the AISI 4340 steel has been extensively studied in the past [6-9].

Most authors reported a constant decrease of hardness with increasing tempering temperature in the range $200{ }^{\circ} \mathrm{C}$ to $600^{\circ} \mathrm{C}[6,7]$. The specific hardness level depends on the tempering duration, and it is slightly lower for longer tempering times [6]. Tensile properties (yield and tensile strength) also steadily decrease with increasing tempering temperature, with more pronounced variations corresponding to longer tempering times [6]. The effect on elongation and reduction of area is a moderate increase with increasing tempering temperature $[6,7]$.

Studies that dealt with the effect of tempering temperature on the impact toughness of 4340 steel, measured either from V-notch or Izod specimens [8, 9], reported that absorbed energy reaches a minimum between $250^{\circ} \mathrm{C}$ and $300^{\circ} \mathrm{C}$ and steadily increases up to $650{ }^{\circ} \mathrm{C}$, where energies between $100 \mathrm{~J}$ and $120 \mathrm{~J}$

\footnotetext{
3 "Pilot lot" indicates a first group of 100 Charpy specimens that each vendor will ship to NIST for preliminary qualification (based on hardness measurements and Charpy tests). If the results are deemed acceptable, many more specimens (more than 1000) are sent to NIST. This constitutes the so-called "production lot," from which another 100 specimens are characterized. If testing of the production lot is also successful, the lot is qualified, and the reference value of absorbed energy is calculated based on the combined results of the pilot and production lots or the production lot alone [4].

${ }^{4}$ With respect to the direction of pendulum swing.
} 
were obtained [9]. Reference [4], however, shows an almost constant value of impact toughness as a function of tempering temperature in the range $280^{\circ} \mathrm{C}$ to $390{ }^{\circ} \mathrm{C}$ (Fig. 1).

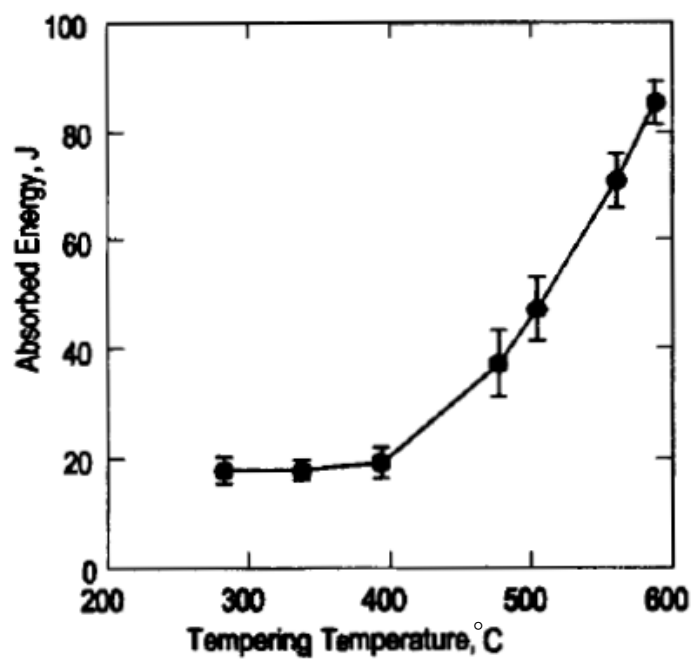

Fig. 1. Effect of tempering temperature on RT absorbed energy for the 4340 steel [4].

The cooling rate after tempering can also influence the mechanical properties of the steel. While tensile properties do not seem to be affected, impact toughness can be decreased if the steel is cooled slowly through the temperature range from $575^{\circ} \mathrm{C}$ to $375^{\circ} \mathrm{C}$ [6]. This phenomenon is called temper embrittlement.

Using the 13 Charpy specimens remaining after testing the two samples in the UT condition (Table 3), we investigated the effect of $T_{\mathrm{FT}}$ in the range $200{ }^{\circ} \mathrm{C}$ to $350{ }^{\circ} \mathrm{C}$ on hardness, impact toughness, and postimpact behavior.

Specimens were heat treated in a small environmental chamber that provided temperature control better than $\pm 5^{\circ} \mathrm{C}$ for $3 \mathrm{~h} \pm 5 \mathrm{~min}$, followed by ambient air cooling $\left(20^{\circ} \mathrm{C}\right) . T_{\mathrm{FT}}$ was varied between $200^{\circ} \mathrm{C}$ and $350{ }^{\circ} \mathrm{C}$, in steps of $50^{\circ} \mathrm{C}$. After tempering, specimens were first measured for hardness and then impact tested at RT $\left(21^{\circ} \mathrm{C} \pm 1{ }^{\circ} \mathrm{C}\right)$ on the TK machine. In addition, two fully treated specimens from LL161 were re-tempered (FHT+RT) at $300^{\circ} \mathrm{C}$ for $3 \mathrm{~h}$, and then air cooled.

Hardness and absorbed energy results are collected in Table 5, which also includes, for comparison purposes, the data from the FHT and UT specimens already presented in Tables 3 and 4.

Hardness and absorbed energy are also plotted in Fig. 2 as a function of $T_{\mathrm{FT}}$. Our results are in qualitative agreement with published data [6-9], insofar as they show decreasing hardness with increasing $T_{\mathrm{FT}}$, while impact toughness exhibits a lower plateau between $300{ }^{\circ} \mathrm{C}$ and $350^{\circ} \mathrm{C}$. 
Table 5. Test results at RT for Charpy specimens of 4340 steel (LL-161).

\begin{tabular}{|c|c|c|c|c|c|}
\hline Condition & $\begin{array}{c}\text { Number of } \\
\text { tests }\end{array}$ & HRC & $\begin{array}{l}K V \\
(J)\end{array}$ & $\begin{array}{l}\text { Postimpact behavior } \\
\text { Direction of travel }\end{array}$ & Speed \\
\hline UT & 2 & $\begin{array}{l}54.5 \\
54.5\end{array}$ & $\begin{array}{l}27.07 \\
26.26\end{array}$ & Both tests: backward & High \\
\hline$T_{\mathrm{FT}}=200^{\circ} \mathrm{C}$ & 2 & $\begin{array}{l}52.2 \\
52.3\end{array}$ & $\begin{array}{l}24.74 \\
25.75\end{array}$ & $\begin{array}{l}\text { Test 1: } 1 / 2 \text { forward, } 1 / 2 \text { on base (front) } \\
\text { Test 2: forward }\end{array}$ & Low \\
\hline$T_{\mathrm{FT}}=250^{\circ} \mathrm{C}$ & 2 & $\begin{array}{l}51.2 \\
52.2\end{array}$ & $\begin{array}{l}19.99 \\
19.79\end{array}$ & $\begin{array}{l}\text { Test 1: on base (front) } \\
\text { Test 2: backward }\end{array}$ & Low \\
\hline$T_{\mathrm{FT}}=300^{\circ} \mathrm{C}$ & 7 & $\begin{array}{l}49.4 \\
49.4 \\
49.1 \\
49.5 \\
49.1 \\
49.6 \\
49.5\end{array}$ & $\begin{array}{l}17.18 \\
16.78 \\
17.74 \\
16.98 \\
17.18 \\
16.98 \\
17.68\end{array}$ & All tests: backward & High \\
\hline$T_{\mathrm{FT}}=350^{\circ} \mathrm{C}$ & 2 & $\begin{array}{l}47.9 \\
47.5\end{array}$ & $\begin{array}{l}16.88 \\
17.58\end{array}$ & Both tests: On base ( $1 / 2$ front, $1 / 2$ back) & Low \\
\hline $\begin{array}{c}\text { FHT } \\
\left(T_{\mathrm{FT}}=357^{\circ} \mathrm{C}\right)\end{array}$ & 2 & $\begin{array}{l}46.8 \\
47.2\end{array}$ & $\begin{array}{l}18.48 \\
17.78\end{array}$ & $\begin{array}{l}\text { Test 1: } 1 / 2 \text { forward, } 1 / 2 \text { on base (front) } \\
\text { Test 2: backward }\end{array}$ & Low \\
\hline $\begin{array}{c}\mathrm{FHT}+\mathrm{RT} \\
\left(T_{\mathrm{FT}}=300^{\circ} \mathrm{C}\right)\end{array}$ & 2 & $\begin{array}{l}47.3 \\
46.7\end{array}$ & $\begin{array}{l}18.78 \\
18.98\end{array}$ & $\begin{array}{l}\text { Test 1: on base (front) } \\
\text { Test 2: forward }\end{array}$ & Low \\
\hline
\end{tabular}

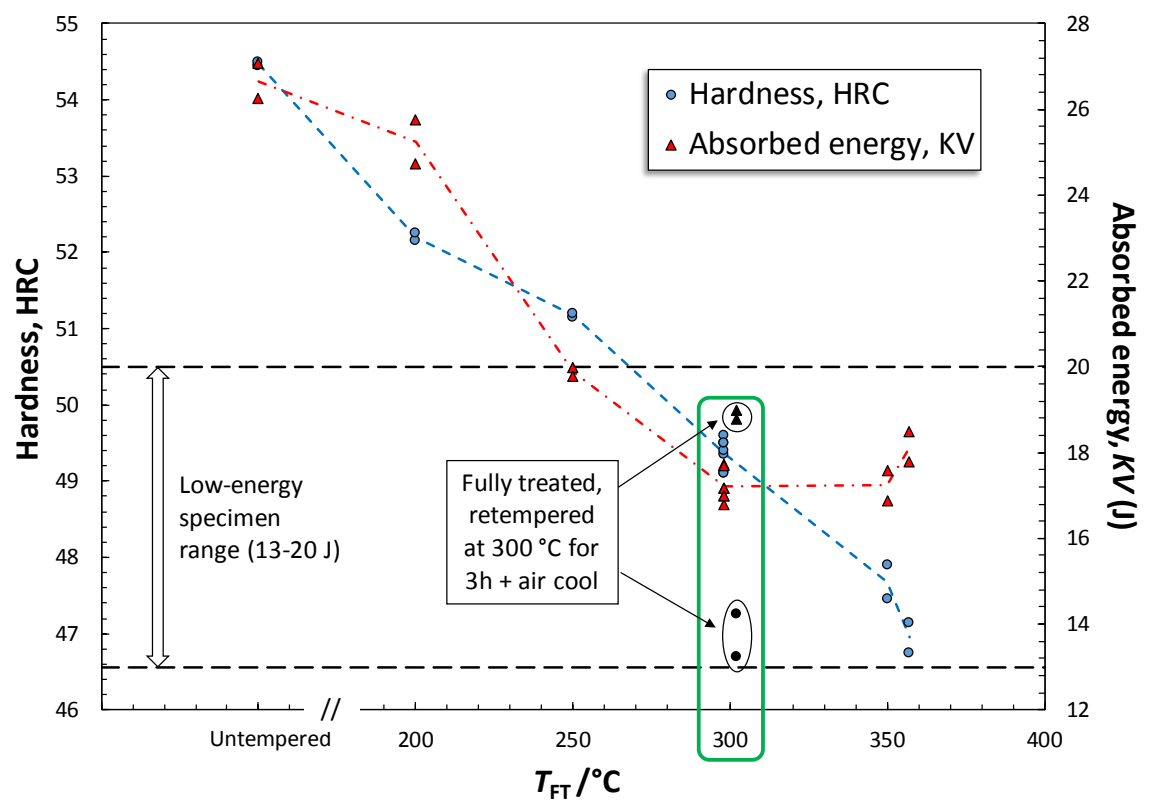

Fig. 2. Hardness and Charpy absorbed energy as a function of final tempering temperature.

Our results show that the most favorable conditions to minimize the possibility of jamming are obtained when low-energy 4340 specimens are tempered for $3 \mathrm{~h}$ at $300^{\circ} \mathrm{C}$, followed by air cooling. Specifically, the postimpact behavior (specimen halves ejected backward at high speed) is the same as conventional low-energy specimens at $-40{ }^{\circ} \mathrm{C}$, while the absorbed energy is $26 \%$ higher, but still well within the typical range for low-energy specimens (13 J to $20 \mathrm{~J}$ ). Hardness, on the other hand, is significantly higher (49.4 HRC vs. 47.0 HRC). 
Details of the seven tests performed on the specimens tempered at $300{ }^{\circ} \mathrm{C}$ are presented in Table 6 , along with average values, standard deviations $(\sigma)$, and coefficients of variation $(C V)$.

Table 6. Detailed results obtained from the specimens tempered at $300{ }^{\circ} \mathrm{C}$.

\begin{tabular}{|ccc|}
\hline $\begin{array}{c}\text { Specimen } \\
\text { ID }\end{array}$ & HRC & $\begin{array}{c}\text { KV } \\
(\mathbf{J})\end{array}$ \\
\hline 5 & 49.35 & 17.18 \\
\hline 6 & 49.40 & 16.78 \\
\hline 11 & 49.10 & 17.74 \\
\hline 12 & 49.50 & 16.98 \\
\hline 13 & 49.10 & 17.18 \\
\hline 14 & 49.60 & 16.80 \\
\hline 15 & 49.50 & 17.68 \\
\hline Average & $\mathbf{4 9 . 3 6}$ & $\mathbf{1 7 . 1 9}$ \\
\hline $\boldsymbol{\sigma}$ & $\mathbf{0 . 2 0}$ & $\mathbf{2 . 3}$ \\
\hline $\boldsymbol{C V}$ & $\mathbf{0 . 0 0 4}$ & $\mathbf{0 . 0 2 1}$ \\
\hline & &
\end{tabular}

One of the most important acceptance criteria for a verification lot by the Charpy program at NIST is based on the sample size, $n_{\mathrm{SS}}$, calculated from pilot and production tests. The value of $n_{\mathrm{SS}}$ represents the minimum number of specimens from a given lot that should be tested for the indirect verification test of a Charpy machine, and it represents a very important statistical metric for assessing the quality of the reference specimen lot. It is defined as $[4,10]$ :

$$
n_{\mathrm{ss}}=\left(\frac{3 s_{\mathrm{p}}}{E}\right)^{2},
$$

where $s_{\mathrm{p}}$ is the pooled standard deviation [11], given by

$$
s_{\mathrm{p}}=\sqrt{\frac{s_{1}^{2}+s_{2}^{2}+s_{3}^{2}}{3}},
$$

with $s_{i}=$ standard deviation for the ith machine, and $E=$ the larger of $1.4 \mathrm{~J}$ or $5 \%$ of the grand mean of the absorbed energy.

For a verification lot (pilot and/or production) to be acceptable, the sample size $n_{\mathrm{Ss}}$ needs to be less than or equal to 5.0 , since sets of NIST verification specimens consist of 5 samples.

For LL-161, the sample sizes calculated from the pilot and the production lots, both based on three machines and 75 tests at $-40{ }^{\circ} \mathrm{C}$ for each lot, were 3.94 and 2.32, respectively. Using the RT absorbed energies listed in Table 6, a sample size of 0.61 is obtained. Although the number of data points is less than $10 \%$ of the number of results constituting a pilot or production lot (75), our results indicate that neither the change in test temperature nor the modification of the heat treatment has a detrimental effect on the material's homogeneity. This is consistent with the findings of our earlier investigation on the feasibility of $\mathrm{RT}$ verification specimens [3].

Based on the results obtained, we plan to ask vendor A (the one who provided the untempered specimens) to change the temperature of the final tempering from $357^{\circ} \mathrm{C}$ to $300^{\circ} \mathrm{C}$ for low-energy specimens. This should allow testing at RT with a minimal risk of jamming (not higher than for current tests at $-40^{\circ} \mathrm{C}$ ). 


\section{Relationship between Hardness and Absorbed Energy for Low-Energy Verification Specimens}

The other three vendors (B, C, and D) were not willing to share with us any information about their heat treatments. We therefore decided to use a different strategy, namely, require a higher minimum hardness level for low-energy specimens (it is currently $44 \mathrm{HRC}$ for specimens tested at $-40{ }^{\circ} \mathrm{C}$ ). In order to establish this new requirement, we performed a number of RT tests on low-energy specimens from currently available lots.

We examined the values of hardness and absorbed energy $\left(\right.$ at $-40^{\circ} \mathrm{C}$ ) for 12 low-energy production lots currently on sale, in order to analyze a possible correlation between these two variables. The results collected are summarized in Table 7 and plotted in Fig. 3, considering average absorbed energies only from the TK machine $\left(K V_{\text {ТК}}\right)$ and from the three reference machines $\left(K V_{\text {all }}\right)$. Historically, the TK machine has always provided consistently lower absorbed energy values than the remaining reference machines at the low-energy level. This was recently highlighted in a study of historical data for the NIST reference machines [12], which attributed this behavior to the stiffer design of the TK machine, as demonstrated by measurements of machine compliance performed in the framework of another investigation [13].

Table 7. Hardness and average absorbed energies at $-40^{\circ} \mathrm{C}$ for 12 low-energy production lots.

\begin{tabular}{|c|c|c|c|c|}
$\begin{array}{c}\text { Lot } \\
\text { ID }\end{array}$ & Vendor & HRC & $\begin{array}{c}\boldsymbol{K V}_{\text {TK }} \\
(\mathbf{J})\end{array}$ & $\begin{array}{c}\boldsymbol{K} \boldsymbol{V}_{\text {all }} \\
(\mathbf{J})\end{array}$ \\
\hline LL-135 & A & 47.31 & 14.27 & 15.54 \\
LL-136 & B & 45.03 & 16.05 & 17.05 \\
LL-144 & A & 46.71 & 13.66 & 15.15 \\
LL-146 & A & 46.50 & 13.98 & 15.01 \\
LL-147 & A & 46.52 & 13.85 & 14.96 \\
LL-149 & C & 46.70 & 14.62 & 15.59 \\
LL-151 & C & 44.37 & 16.59 & 17.64 \\
LL-155 & A & 46.78 & 14.13 & 15.29 \\
LL-156 & A & 47.12 & 14.45 & 15.95 \\
LL-161 & A & 47.32 & 14.42 & 15.54 \\
LL-162 & A & 47.04 & 14.68 & 15.82 \\
LL-165 & D & 45.73 & 12.08 & 13.00 \\
\hline \multicolumn{5}{|r}{}
\end{tabular}

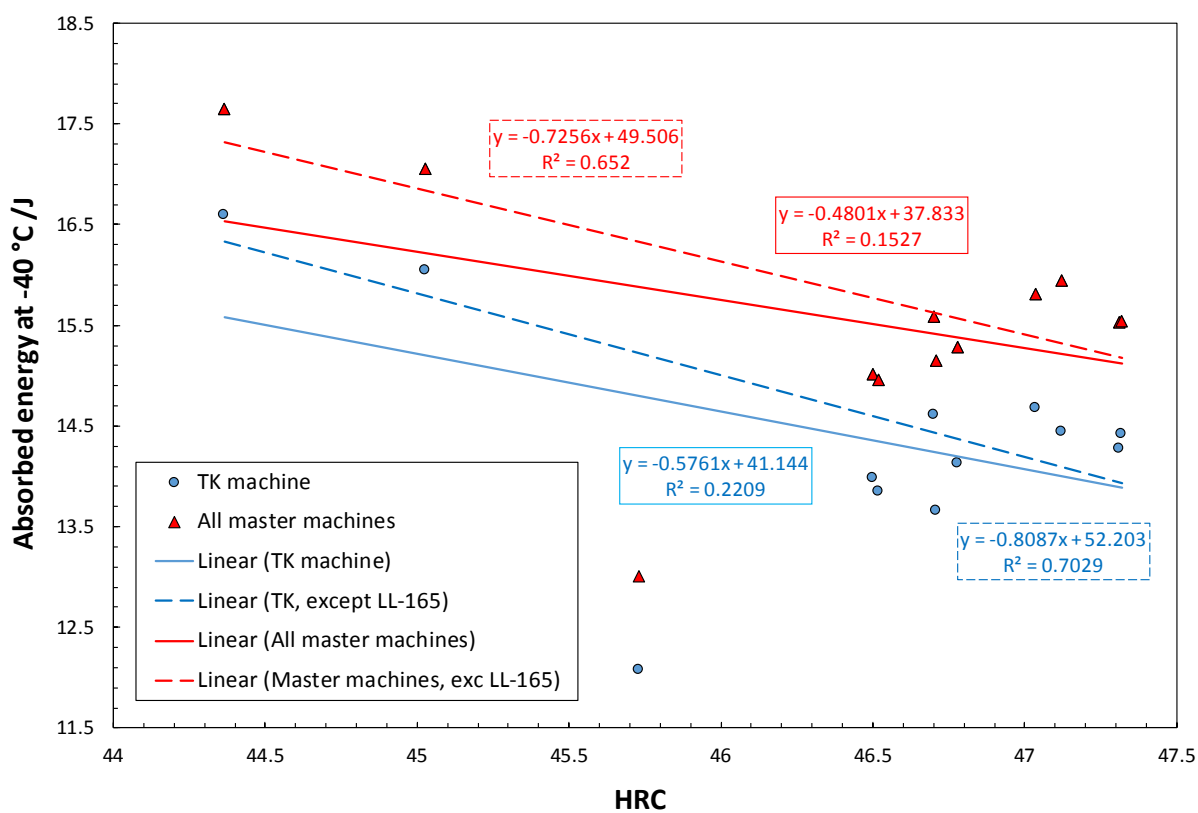

Fig. 3. Relationship between hardness and energy absorbed at $-40{ }^{\circ} \mathrm{C}$ for 12 low-energy verification lots. 
Figure 3 indicates that absorbed energy decreases as hardness increases, but the degree of correlation is weak or moderate, ${ }^{5}$ unless the LL-165 lot (which appears to be an outlier) is removed, in which case the correlation coefficients ${ }^{6}$ change from $-0.46999\left(K V_{\mathrm{TK}}\right)$ and $-0.39082\left(K V_{\text {all }}\right)$ to -0.83839 and -0.80749 , respectively. The reason for the outlier behavior of LL-165 is not apparent; however, we note that it is the only lot in Table 7 that came from vendor $\mathrm{D}$, and therefore its results could depend on the specific heat treatment applied (which is different for each of our vendors).

We selected 4 of the 12 lots in Table 7 for Charpy tests at RT, two with HRC $<47$ and two with HRC $>47$. Four or six specimens were tested on the TK machine for each lot, and for every test the post-impact behavior was recorded. The results are provided in Table 8, while Fig. 4 illustrates the relationship between hardness and RT absorbed energy.

Table 8. Hardness and RT absorbed energy for four low-energy verification lots.

\begin{tabular}{|c|c|c|c|c|}
\hline $\begin{array}{l}\text { Lot } \\
\text { ID }\end{array}$ & HRC & Vendor & $\begin{array}{c}K V_{\text {TK }} \\
(J)\end{array}$ & Postimpact behavior \\
\hline LL-135 & 47.31 & A & $\begin{array}{l}17.13 \\
20.19 \\
17.28 \\
17.68\end{array}$ & $\begin{array}{c}\text { Backward }(v=\text { medium) } \\
\text { On base (back) } \\
\text { On base (back) } \\
1 / 2 \text { backward }(v=\text { low); } 1 / 2 \text { on base (back) }\end{array}$ \\
\hline LL-151 & 44.37 & $\mathrm{C}$ & $\begin{array}{l}25.13 \\
24.43 \\
23.92 \\
23.62\end{array}$ & All tests: forward ( $v=$ medium $)$ \\
\hline LL-161 & 47.32 & A & $\begin{array}{l}17.28 \\
17.38 \\
19.18 \\
16.77 \\
18.08 \\
17.48\end{array}$ & $\begin{array}{c}\text { On base ( } 1 / 2 \text { front, } 1 / 2 \text { back) } \\
1 / 2 \text { backward ( } v=\text { medium); } 1 / 2 \text { on base (front) } \\
\text { On base (front) } \\
\text { Backward ( } v=\text { low) } \\
\text { On base ( } 1 / 2 \text { front, } 1 / 2 \text { back) } \\
\text { On base (front) }\end{array}$ \\
\hline LL-165 & 45.73 & $\mathrm{D}$ & $\begin{array}{l}15.87 \\
15.17 \\
14.77 \\
16.47\end{array}$ & $\begin{array}{c}1 / 2 \text { on base (front); } 1 / 2 \text { forward }(v=\text { low }) \\
\text { On base }(1 / 2 \text { front, } 1 / 2 \text { back }) \\
\text { On base (front) } \\
\text { Forward }(v=\text { medium })\end{array}$ \\
\hline
\end{tabular}

The data presented in Table 8 indicate that a hardness level of 47 HRC is not sufficient to exclude specimen jamming at RT. Therefore, a higher minimum hardness level is needed. Considering that the average measured hardness was $49.4 \mathrm{HRC}$ for specimens tempered at $300^{\circ} \mathrm{C}$, we will set the minimum hardness level for RT low-energy verification specimens to 49 HRC. This decision is based on an engineering judgment, resulting from the limited number of data available, and it will be subjected to periodical reevaluations.

The results depicted in Fig. 4 confirm the trends previously observed on $-40{ }^{\circ} \mathrm{C}$ tests (Fig. 3): When the outlier lot LL-165 is removed from the relationship, the correlation coefficient between hardness and absorbed energy changes from -0.63997 to -0.95536 .

\footnotetext{
${ }^{5}$ Conventionally, a correlation is very weak when $R$ is between 0 and 0.19 , weak between 0.2 and 0.39 , moderate between 0.4 and 0.59 , strong between 0.6 and 0.79 , and very strong between 0.8 and 1 [14].

${ }^{6}$ Correlation coefficients are negative because absorbed energy decreases as hardness increases.
} 


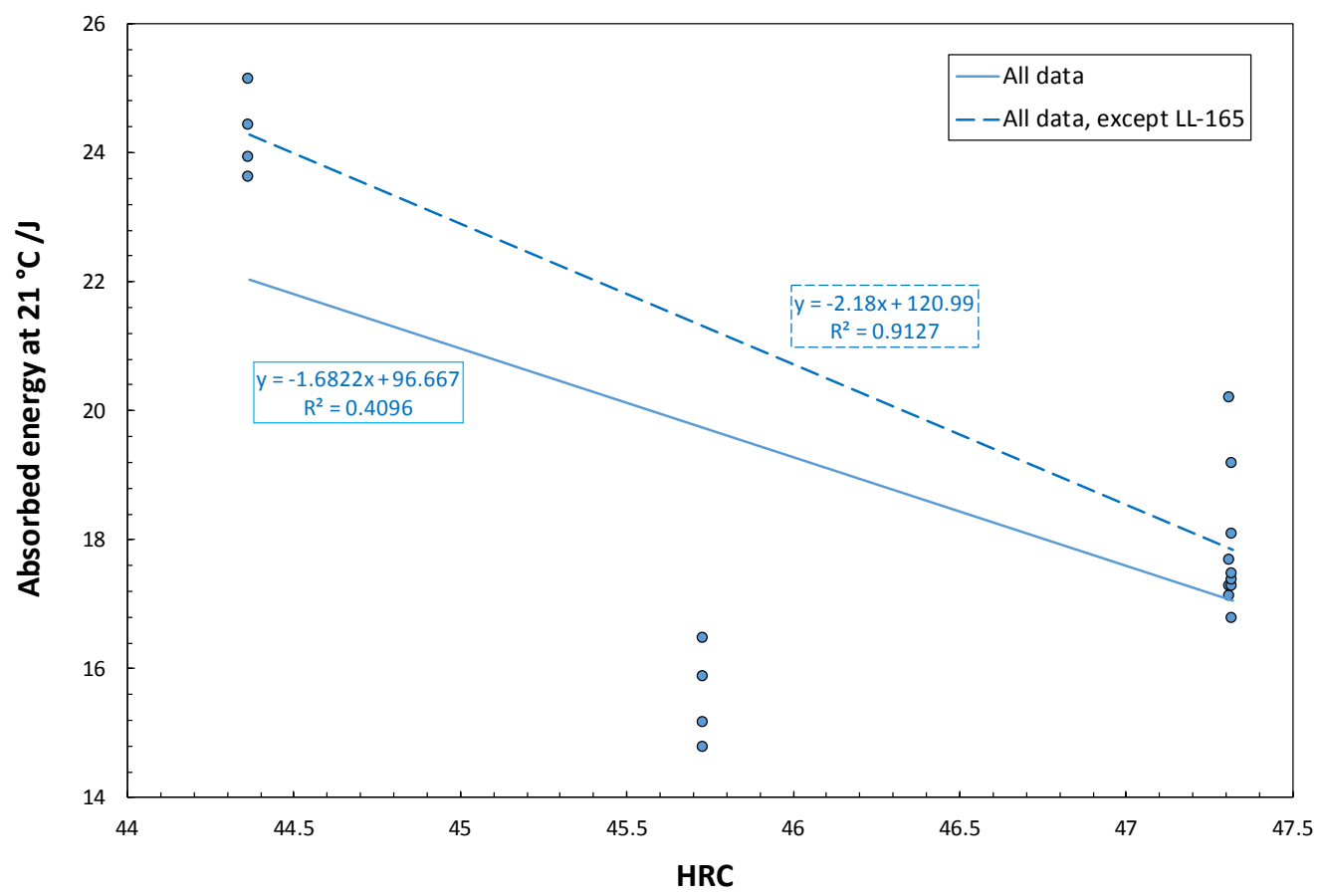

Fig. 4. Relationship between hardness and absorbed energy at $21^{\circ} \mathrm{C}(\mathrm{RT})$ for four low-energy verification lots.

\section{Conclusions}

Despite being based on a limited number of available specimens, this study allowed us to identify a suitable modification in the heat treatment of 4340 steel. This modification is desirable in order for the behavior of low-energy verification specimens, during and after impact at $\mathrm{RT}\left(21^{\circ} \mathrm{C} \pm 1{ }^{\circ} \mathrm{C}\right)$, to be equivalent to that of current specimens tested at $-40^{\circ} \mathrm{C}$. The required modification consists of lowering the temperature of the final tempering treatment from $357^{\circ} \mathrm{C}$ (according to the information provided by one of our vendors) to $300{ }^{\circ} \mathrm{C}$ for $2 \mathrm{~h}$, followed by air cooling. Specimens tempered at $300{ }^{\circ} \mathrm{C}$ exit the machine backward at high velocity (thus minimizing the chance of jamming) and exhibit toughness properties that are fully comparable to those of current specimens when tested at $-40{ }^{\circ} \mathrm{C}$.

For those vendors who were unwilling to share with us information about their heat treatment, we plan to change the requirement for the minimum Rockwell C hardness of low-energy specimens from 44 HRC to 49 HRC. Although some undesirable postimpact behavior (specimen halves falling on the machine base) was observed even for specimens with hardness as high as 51 HRC to 52 HRC, we believe that the change in the hardness requirement will prompt those vendors to modify the temperature of the final tempering treatment and therefore provide us with the desired RT impact toughness properties.

\section{References}

[1] ASTM E23-12c (2015) Standard Test Methods for Notched Bar Impact Testing of Metallic Materials, ASTM Book of Standards (ASTM International, West Conshohocken, PA), Vol. 03.01.

[2] Driscoll DE (1956) Reproducibility of Charpy impact test. Symposium on Impact Testing, ASTM STP 176, Tatnall F, Ed. (ASTM International, Philadelphia, PA), pp 70-75. http://dx.doi.org/10.1520/STP47578S

[3] Lucon E, McCowan CN, Santoyo RL, (2015) Certification of NIST room temperature low-energy and high-energy Charpy verification specimens. Journal of Research of the National Institute of Standards and Technology 120:316-328. http://dx.doi.org/10.6028/jres.120.020 
[4] McCowan CN, Siewert TA, Vigliotti DP (2003) The NIST Charpy V-notch verification program: Overview and operating procedures. In Charpy Verification Program: Reports Covering 1989-2002. U.S. Department of Commerce, Washington, D.C., NIST Technical Note 1500-9, Materials Reliability Series, pp 3-42.

[5] R. Heist, e-mail to E. Lucon, October 18, 2016.

[6] Chandler H, Ed (1995) Heat Treater's Guide —Practices and Procedures for Irons and Steels (ASM International, Materials Park, OH), 2nd Ed.

[7] Lee W-S, Su TT (1999) Mechanical properties and microstructural features of AISI 4340 high-strength alloy steel under quenched and tempered conditions. Journal of Materials Processing Technology 87:198-206. http://dx.doi.org/10.1016/S09240136(98)00351-3

[8] Zhirafar S, Rezaeian A, Pugh M (2007) Effect of cryogenic treatment on the mechanical properties of 4340 steel. Journal of Materials Processing Technology 186:298-303. http://dx.doi.org/10.1016/j.jmatprotec.2006.12.046

[9] Campbell FC, Ed. (2008) Elements of Metallurgy and Engineering Alloys (ASM International, Materials Park, OH).

[10] Wang CM, Splett JD (1997) Consensus values and reference values illustrated by the Charpy Machine Certification Program. Journal of Testing and Evaluation 25(3):308-314. http://dx.doi.org/10.1520/JTE11343J

[11] Killeen PR (2005) An alternative to null-hypothesis significance tests. Psychological Science 16(5):345-353. http://dx.doi.org/10.1111/j.0956-7976.2005.01538.x

[12] Lucon E, Santoyo RL (2016) A Comparative Analysis of NIST Charpy Machines and Internal Reference Materials. U.S. Department of Commerce, Washington, D.C., NIST Interagency/Internal Report (NISTIR) 8145. https://dx.doi.org/10.6028/NIST.IR.8145

[13] Lucon E (2015) Determination of the Compliance of NIST Charpy Impact Machines. U.S. Department of Commerce, Washington, D.C., NIST Interagency/Internal Report (NISTIR) 8043. https://dx.doi.org/10.6028/NIST.IR.8043

[14] Campbell MJ, Swinscow TDV (1997) Statistics at Square One (BMJ Publishing Group, London), 9th Ed. ISBN-13: 9780727915528

About the authors: Enrico Lucon is a materials engineer in the Applied Chemicals and Materials Division of the National Institute of Standards and Technology (NIST) in Boulder, Colorado, where he has worked since 2010. Originally from Milan (Italy), he worked previously at CISE Milan (1986-1998) and at SCK・CEN, the Belgian Nuclear Research Center (1998-2010).

Ray Santoyo has 25 years of mechanical testing experience and has been the Charpy program coordinator at NIST Boulder since 2004. He is currently also the Charpy project leader. Prior to this, he worked in the NIST Mechanical Testing Laboratory in Boulder, Colorado.

The National Institute of Standards and Technology is an agency of the U.S. Department of Commerce. 